\title{
VIOLÊNCIA NA ESCOLA, PRÁTICAS EDUCATIVAS E FORMAÇÃO DO PROFESSOR
}

MARIA AUGUSTA SALIN GONÇALVES

Programa de Pós-Graduação em Educação da Universidade do Vale do Rio dos Sinos São Leopoldo/RS

guta@unisinos.br; guta.voy@terra.com.br

\section{ORENE MARIA PIOVESAN}

orene@terra.com.br

ANDRISA LINK

andrisa@unisinos.br

LUSIANA F. PRESTES

lusiana@unisinos.br

JOICIANA G. LISBOA

joiciana@unisinos.br

Graduados/Graduandos em Educação pela Universidade do Vale do Rio dos Sinos

\section{RESUMO}

O objetivo dessa investigação é compreender as possibilidades e limites de uma experiência de formação continuada de professores de ensino fundamental que lidam com adolescentes de periferia. Realizada em 2002, com 10 professores, em 15 reunióes, a pesquisa pretendeu compartilhar momentos de reflexão e diálogo, buscando minimizar a violência na escola. Discutimos teorias do desenvolvimento da moralidade e trabalhamos com os professores açóes educativas (dramatização, dilemas morais e dinâmicas de grupo) que visam a favorecer a emergência de interação social construtiva. As reuniões foram analisadas com procedimentos hermenêuticos. Na sistematização dos resultados, examinamos, inicialmente, a experiência como um todo. A seguir, destacamos momentos pedagógicos significativos, em que os professores compartilharam conosco experiências educativas realizadas no período dos encontros.

ADOLESCÊNCIA - VIOLÊNCIA - EDUCAÇÃO CONTINUADA - PROFESSORES

O texto está vinculado ao projeto de pesquisa desenvolvido no Programa de Pós-Graduação em Educação da Universidade do Vale do Rio dos Sinos - Unisinos -, intitulado "Formação do educador, saberes éticos e cidadania: pesquisa-ação no contexto da escola". As alunas Orene e Joiciana são bolsistas da Fundação de Amparo à Pesquisa do Estado do Rio Grande do Sul - Fapergs —- Andrisa é bolsista do Programa Institucional de Bolsas de Iniciação Científica - Pibic/CNPq - e Lusiana, do Programa de Bolsas de Iniciação Científica da Unisinos - Unibic. 


\section{ABSTRACT}

VIOLENCE IN THE SCHOOLS, EDUCATIONAL PRACTICES AND TEACHERS' TRAINING. The goal of this investigation is to understand the possibilities and limitations of an experience of continued education for primary school teachers who deal with adolescents from poor neighbourhoods. The study was conducted in 2002 and involved 10 teachers and 15 meetings, which were occasions for sharing reflections on how to minimize violence in the schools. We discussed theories of moral development and carried out educational activities (dramatization, moral dilemmas, and group dynamics) to encourage the emergence of constructive social interaction among the teachers. Meetings were assessed according to hermeneutic methods. In the systematization of results, we initially examined the experience as a whole. Next, we focused on significant pedagogical moments in the meetings, in which the teachers shared with us their educational experiences.

ADOLESCENCE - VIOLENCE - RECURRENT EDUCATION - TEACHERS

No momento atual, a violência é um fenômeno que se observa com freqüência crescente em todos os domínios da vida social. Esse fenômeno também ocorre na escola, onde professores e alunos vivenciam no seu cotidiano diferentes formas de violência. Pesquisas realizadas sobre a temática relatam suas manifestações, procurando entender as raízes socioculturais, econômicas e familiares do fenômeno (Colombier, Mangel, Perdriault, 1989; Estrela, 1994).

Existe grande perplexidade da parte do professor que, muitas vezes, fica sem saber como agir para resolver e prevenir os múltiplos conflitos que surgem no cotidiano escolar. O que se observa é que, na maioria das vezes, ele tem muitas dificuldades de lidar com as situações de conflito, de forma a propiciar ao aluno experiências educativas de interação social construtiva que favoreçam a sua formação ética e minimizem a violência na escola. Em contrapartida, pensamos que a escola é o espaço por excelência em que o indivíduo tem possibilidades de vivenciar de modo intencional e sistemático formas construtivas de interação, adquirindo um saber que propicie as condições para o exercício da cidadania.

Com base nessas reflexões, o objetivo deste trabalho é apresentar e discutir os resultados de investigação realizada para compreender as possibilidades e limites de uma experiência de formação continuada de professores de ensino fundamental que lidam com adolescentes de periferia, onde há muitos problemas de violência que se repetem no cotidiano da escola. Definimos "violência" como o "uso da força física e do constrangimento psíquico para obrigar alguém a agir de modo contrário à sua natureza e ao seu ser. A violência é vio- 
lação da integridade física e psíquica, da dignidade humana de alguém" (Chauí, 1995, p.337).

Consideramos que esta experiência se insere no âmbito da formação continuada do professor no contexto da escola. Buscamos fundamentar suas idéias norteadoras em autores como Freire (1985, 1994, 1997), Marques (2000), Perrenoud (1997), Tardif (2002), Schön (1995), Zeichner (1995). Das reflexões propiciadas pelo diálogo com esses autores, emergiram algumas diretrizes que orientaram nossa atuação nas reuniões com o grupo de professores.

Em primeiro lugar, colocamo-nos diante dos professores não como quem domina o saber e quer ditar a forma como eles deveriam agir diante dos alunos. Nossa atitude foi a de cooperar, isto é, de trabalhar junto com eles, buscando compreender as situações específicas que constituíam o motivo das discussões. Em alguns momentos, trouxemos conhecimentos teóricos para ajudar a entender melhor o que se passava. A validade desses conhecimentos não estava, entretanto, no poder explicativo geral de uma determinada teoria, muito menos no seu prestígio acadêmico, mas, no potencial para elucidar aspectos da situação concreta que era alvo de nosso diálogo. A explicação do professor foi de antemão valorizada, podendo, conforme a discussão, ter sido confirmada, ampliada, aprofundada ou contraposta, mas nunca ignorada ou totalmente negada.

Em segundo lugar, sempre procuramos resgatar a auto-estima do professor, compreendendo seus limites, suas frustrações e sua perplexidade diante da violência que ocorre na escola. Procuramos sempre valorizar os esforços em busca de uma prática pedagógica significativa.

Em terceiro lugar, nossa postura foi sempre considerar o professor como parceiro do diálogo em que, juntos, buscaríamos construir algo novo. Sendo assim, íamos para as reuniões com abertura para ouvi-los e, a partir de suas manifestações, orientar as discussão.

\section{REALIZAÇÃO DA EXPERIÊNCIA}

A experiência ocorreu durante o ano de 2002. Foram realizadas I 5 reuniões quinzenais, com duração de aproximadamente uma hora, com dez professores (nove professoras e um professor) de uma escola de ensino fundamental de periferia. $O$ objetivo foi compartilhar com os professores das sextas e sétimas séries momentos de reflexão e diálogo, que os auxiliassem a lidar com 
os alunos-adolescentes visando a minimizar a violência que permeia a convivência na escola. As discussões se estabeleceram com base em informações trazidas pelos professores, como problemas de interação social, conflitos e situações de violência ocorridos na escola. A atitude da equipe sempre foi a de inicialmente ouvir os professores, tentar compreender suas manifestações e, por meio de questões e comentários, permitir que emergissem reflexões que pudessem apontar para novas formas de agir diante de situações conflituosas. Discutimos teóricos que tratam de questões referentes à formação da consciência moral, à psicologia do desenvolvimento e, em especial, à adolescência.

Nos encontros, as questões teóricas somente foram discutidas quando serviam para explicitar os momentos vividos pelos professores no cotidiano e relatados para o grupo. Com essa inversão da teoria e da prática, pretendemos evitar que a teoria fique fechada em si mesma, sem que nada possa ser negado ou transformado. Queremos que ela cumpra o papel de ampliar a leitura do real com novos referenciais, abrindo perspectivas para enxergar e sentir o mundo que nos rodeia. Nesse sentido, apoiamo-nos, por vezes, no que se refere à adolescência, em teóricos da psicologia do desenvo/vimento, como Piaget (1 994), Kohlberg (1984), Gilligan (1994), Habermas (1989), Puig (I 998, 1999), Erikson (1976), Cullen (1996), Knobel (1997), Levisky (1997) entre outros.

Também trabalhamos, com os professores, ações educativas que podem ser realizadas em sala de aula. Elas buscam criar situações em que o adolescente participe de forma ativa e traga à tona seus conflitos, frustrações e aspirações, assuma-os, refletindo sobre eles e discutindo com os outros, buscando solucioná-los de forma construtiva.

\section{Ações educativas}

Partimos do pressuposto de que a ação educativa que visa à formação para cidadania e procura favorecer a emergência de interação social construtiva deve estar integrada no cotidiano escolar, de tal forma que o professor seja capaz de aproveitar os múltiplos momentos de conflito que surgem na escola para contribuir de forma eficiente para essa formação. Pensamos ainda que cabe ao professor criar situações educativas que possibilitem a internalização de normas sociais construtivas pelo aluno. Na literatura pedagógica, há muitas sugestões de ações educativas dessa natureza, que, embora muitas vezes apre- 
sentadas como técnicas isoladas e descontextualizadas, se consideradas dentro de uma perspectiva integradora, podem constituir um instrumento valioso para possibilitar ao aluno vivências de interação social construtiva.

Nosso trabalho baseia-se em três tipos de ações educativas: a dramatização, a discussão em torno de dilemas e a realização de dinâmicas de grupo.

A seguir, tratamos especificamente de cada uma dessas ações:

\section{Dramatização}

A dramatização possibilita que os participantes vivenciem os seus conflitos de interação social, liberem tensões e elaborem criativamente novas formas de solução. Na dramatização, a situação é vivenciada como se fosse real, deixando que aflorem emoções, que apareçam conflitos reprimidos e que os participantes se sensibilizem nas relações interpessoais.

Na dramatização, os participantes são ativos, participam com sentimentos e emoções na situação representada. Essa participação certamente é uma forma de produzir mudanças e transformações, fugindo a um verbalismo que procura "aconselhar", definindo "teoricamente" o que é certo ou errado.

Ao trabalhar com dramatização, nos apoiamos no Psicodrama de Moreno e no Teatro do Oprimido de Boal.

O psicodrama foi criado pelo psiquiatra vienense Jacob Levy Moreno ( 1889 - 1974). Essa abordagem tem como base uma visão de homem e de mundo em permanente interação, sendo que, na trama das relações cotidianas, o homem tem condições de recriar-se, transformando a si mesmo e o seu ambiente. $O$ psicodrama visa assim a libertar os potenciais criativos, possibilitando novas formas de lidar com conflitos e de atuar no mundo. Tem como objetivo liberar a espontaneidade, que, para Moreno, "é a nossa capacidade de dar resposta adequada a cada situação, em cada momento em que nos encontramos (...) em função de todas as variáveis de uma situação" (Weil, 1967, p.23).

As diferentes técnicas de psicodrama foram discutidas com os professores e analisadas as suas possibilidades como ações educativas a serem desenvolvidas em sala de aula. Focalizamos principalmente as técnicas do role-playing, que se apresentam em três níveis: 
I. Role-taking - tomada de papel: a pessoa adota um papel e segue a linha do script (duplo, solilóquio espelho).

2. Role-playing: a pessoa treina o papel assumido (imagem, espelho, concretização, inversão de papéis).

3. Role-creating: a pessoa cria um personagem e a respectiva ação (teatro espontâneo, inversão de papéis).

O Teatro do Oprimido é uma forma de psicodrama, trabalhada por Augusto Boal (2000), com modelos teatrais específicos e regras próprias, que o autor desenvolveu em experiências com diferentes grupos étnicos. Seu objetivo maior é permitir vivências de reconhecimento das raízes dos problemas pessoais e sociais, estimulando reflexões que abram caminhos para a busca de soluções criativas para esses problemas, denunciando e recriando relações de poder, liberando da opressão. Segundo o autor, para trabalhar com o Teatro do Oprimido é preciso ter em conta o seu princípio básico, que é: "A imagem do real é real enquanto imagem (...) Devemos trabalhar com a realidade da imagem e não com a imagem da realidade (2000, p.233). Seu valor pedagógico, assim como do psicodrama de Moreno, reside no fato de que na imagem conjugada com a ação há um envolvimento do sentimento, da emoção, atingindo o ser humano de forma radical, "uma imagem não precisa ser entendida, e sim sentida" (Boal, 2000, p.233). As imagens são construídas coletivamente a partir dos problemas típicos de um grupo social. Os espectadores participam ativamente, mantendo um diálogo coletivo que envolve atores e platéia, que seguidamente invertem seus papéis. Como expressa: Boal: "Descobrindo o teatro, o ser se descobre humano. $O$ teatro é isso: a arte de nos vermos a nós mesmos, a arte de nos vermos vendo!" (2000, p.XX).

$\bigcirc$ Teatro do Oprimido é de grande valor educativo no tratamento de temas como discriminação, preconceito, trabalho, violência, entre outros.

Durante as reuniões, quando os professores relataram conflitos ocorridos em sala de aula, procuramos incentivá-los a desenvolver formas de teatro em suas aulas. Com esse objetivo, preparamos também um material sobre Teatro do Oprimido com a descrição das técnicas que mais se adaptam ao ambiente escolar, explicitando o seu significado psicológico:

- Teatro imagem : conjunto de técnicas que utiliza principalmente a imagem concreta para expressar emoções. A linguagem é o gesto que se 
utiliza do próprio corpo ou o corpo do outro, para a expressão de sentimentos e idéias;

- Teatro fórum: usado em casos de situações sociais concretas bem definidas, em que há um conflito a ser resolvido: conflitos entre pais e filhos, desemprego, violência, drogadição, roubo e outras situações que ocorrem na escola. Os participantes têm um papel bem definido e previamente combinado, podendo ser até brevemente ensaiado. A platéia é convidada a discutir sobre a ação dos protagonistas, buscando uma forma melhor de agir.

- Teatro jornal: conjunto de técnicas em que notícias de jornal são dramatizadas, por diferentes formas de interpretação.

- Teatro invisivel: representadas cenas cotidianas onde os espectadores são reais participantes do fato ocorrido, reagindo e opinando espontaneamente na discussão provocada pela encenação.

\section{Dilemas morais}

Os dilemas morais são narrativas breves de situações envolvendo conflitos de natureza moral que encerram valores diferentes. No final da narrativa, o aluno é solicitado a assumir e a justificar, com argumentos, um posicionamento sobre a forma que lhe parece mais justa para resolver a situação conflituosa. Os dilemas morais não oferecem nenhuma resposta certa, mas incentivam o exame de diferentes opções com seus respectivos argumentos.

Kohlberg (1984) baseou a sua investigação sobre o desenvolvimento moral em dilemas morais, ancorados em princípios morais abstratos que estariam na base de normas válidas e universais. De acordo com a teoria do desenvolvimento da inteligência de Jean Piaget, Kohlberg interpreta a passagem de um estágio de julgamento moral a outro superior como o resultado de um processo construtivo, em que as estruturas cognitivas dos julgamentos morais correspondentes a cada estágio são construídas por um processo de reorganização criativa das aquisições cognitivas dos estágios anteriores, quando o indivíduo enfrenta problemas que não consegue resolver e que reaparecem freqüentemente.

Puig ( 1999 ) sistematizou as seguintes características que devem ser consideradas nas aplicações de dilemas morais: 
- Definição clara do âmbito do dilema: o dilema precisa ser suficientemente conhecido pelos alunos, podendo referir-se a fatos reais ou imaginários, não devendo conter informações desnecessárias.

- Definição de um protagonista: os dilemas devem ter sempre protagonistas que experimentam o conflito de valores. Esses devem decidir o que fazer e justificar com argumentos a sua decisão.

- Exigência de uma escolha: o dilema deve propor a escolha entre alternativas conflitivas, que encerram valores em si defensáveis.

- Proposição de temáticas morais: para favorecer o desenvolvimento moral, as temáticas devem possuir conteúdo moral, que tenham em sua base conflitos de interesses individuais e sociais.

- Formulação de questóes: deve ser perguntado ao final da narrativa do dilema "o que deveria fazer o protagonista?" e "por que deveria fazer?", centrando-se a discussão na justificativa da decisão considerada correta pelo protagonista.

- Formulação de questóes e dilemas alternativos: dilemas alternativos, relacionados com o dilema central podem provocar conflito e convidar à reflexão e à discussão, incentivando a visualizá-lo a partir de outras perpectivas.

Puig distingue três tipos de dilemas que podem ser aplicados em sala de aula: dilemas hipotéticos, que descrevem situações distantes da vida real dos alunos; dilemas reais, criados pelo educador, mas que se referem a problemas vivenciados pelos alunos; dilemas criados e redigidos pelos alunos, envolvendo situações relativas a suas vivências pessoais.

Na dinâmica das discussões em torno dos dilemas morais, Puig distingue quatro fases: apresentação do dilema; adoção de uma postura pessoal inicial e primeira discussão com os colegas; discussão do dilema em pequenos grupos; nova reflexão sobre o dilema e sua discussão (1999, p.60).

\section{Dinâmicas de grupo}

Segundo Weil (1967), dinâmica de grupo é expressão utilizada pela primeira vez por Kurt Lewin em seus estudos sobre democracia e autocracia. Esses estudos visavam a obter conhecimentos sobre a natureza, origem e evolução 
dos grupos, sobre as relações entre indivíduos e grupos e sobre a influência das coletividades, sociedades e culturas.

Desde então, dinâmicas de grupo foram objeto de estudo de inúmeros pesquisadores sob diferentes perspectivas teórico-práticas, abrangendo áreas do conhecimento relacionadas com atividades de grupos.

Neste trabalho, as dinâmicas de grupo podem ser entendidas como procedimentos que envolvem ações educativas realizadas com grupos de alunos, visando a favorecer a emergência de interação social construtiva, baseada na comunicação, cooperação, confiança, reciprocidade, respeito mútuo e responsabilidade.

As selecionadas para trabalhar com as professoras visam a atingir esses objetivos e foram traduzidas e adaptadas da obra, de Faller, Kerntke e Wackmann (1996), cujo título pode ser traduzido como: Resolver conflitos por si mesmos: um programa de treinamento para mediação e manejo de conflito na escola e no trabalho com jovens. O objetivo desse programa é apontar possibilidades de estimular em crianças e adolescentes a capacidade para resolver problemas de forma competente, isto é, a comportar-se construtivamente em momentos de conflito, ajudando-os a renunciar à violência, desenvolvendo a capacidade de diálogo e a busca conjunta na solução dos problemas. As dinâmicas são apenas sugestões que devem ser recriadas para as situações específicas que ocorrem em sala de aula. Levando em conta o contexto cultural da escola e os conflitos existentes em um determinado momento, o professor, a partir das idéias trabalhadas nesse programa, pode transformar as dinâmicas, adequando-as aos objetivos pedagógicos que pretende atingir em determinado momento.

\section{MOMENTO INVESTIGATIVO}

Nesta seção, inicialmente descrevemos a escola onde realizamos a pesquisa. A seguir, descrevemos a análise e apresentamos as nossas reflexões.

\section{O contexto da escola}

Trata-se de uma escola municipal de ensino fundamental, situada em um bairro periférico com inúmeros problemas sociais como: miséria, desemprego, falta de saneamento básico, drogas, criminalidade e violência em geral. 
Decidimos por essa escola pelas características referentes à sua localização, e, principalmente, pelo interesse demonstrado pela direção da escola na nossa participação, após vários encontros nos quais expusemos o trabalho. Para que os alunos pudessem ser liberados, a fim de que os professores, por uma hora quinzenal, pudessem participar das reuniões, enviamos o projeto de pesquisa aos órgãos competentes, que atenderam à solicitação da direção.

A escola é toda cercada por muro. Ela abriga alunos da primeira à sétima série e atende três turnos: manhã, tarde e noite. Há controle de entrada e saída das pessoas por um vigia. O espaço físico é composto por 20 salas de aula, uma sala de professores, biblioteca, refeitório, cozinha, duas salas administrativas e uma sala de projetos, seis banheiros, um ginásio de esportes (área com piso e cobertura), um pátio interno e uma horta. As salas de aula são pequenas e as turmas são compostas geralmente de 30 a 40 alunos. A escola possui I 167 alunos no turno diurno e 200 no turno da noite. O corpo docente é composto por 63 professores, com 82 cargos. Conta com cinco funcionários de serviços gerais.

\section{Análise das reuniões}

A análise do material gravado e transcrito das reuniões e do diário de campo realizou-se conforme as etapas descritas a seguir.

Inicialmente, fizemos uma leitura de todo o material para obter uma visão de conjunto. A seguir, destacamos nos textos "unidades de significado", isto é, partes que respondiam às questões que fizemos para orientar a análise: "Qual a percepção dos professores a respeito da violência? Como os professores lidam com os conflitos de interação social ocorridos na escola? Em que momentos as discussões havidas nas reuniões possibilitaram ao professor a introdução de mudanças na sua prática educativa? Quais essas mudanças?". A seguir, procuramos realizar sínteses que descrevessem as ações e reflexões dos professores, tentando compreendê-las no contexto da experiência.

A análise das reuniões será apresentada e discutida em dois momentos. Inicialmente, descreveremos a experiência como um todo. A seguir, destacamos alguns momentos que denominamos "momentos pedagógicos significativos", nos quais os professores compartilharam conosco experiências educativas realizadas com os alunos, que serviram também como ponto de partida para as discussões dos encontros. 


\section{Análise e discussão da experiência como um todo}

A análise nos permitiu destacar alguns pontos para a reflexão:

- queixas dos professores quanto à indisciplina e violência dos alunos e falta de motivação;

- expressão das dificuldades na concretização de mudanças, devido à exigência de horários e de cumprimento de conteúdos curriculares e ao grande número de alunos nas turmas;

- preocupação de orientar os alunos quanto a drogas e sexo, atendendo aos seus interesses;

- reconhecimento crescente da necessidade de introduzir mudanças em suas práticas pedagógicas.

A seguir, trazemos algumas reflexões, sobre esses pontos.

Percepção dos professores quanto a indisciplina e agressividade dos alunos

Em vários momentos das reuniões, os professores manifestaram a sua perplexidade quanto às atitudes dos alunos.

Em relação ao ambiente físico

Para as professoras os alunos não têm cuidado com as coisas da escola, como neste depoimento: "Só sentem prazer em destruir. Olho ao redor, parecem paredes de um presídio. Por mais que seja tudo novinho, já está tudo riscado (...) parece um lixo. O banheiro é a pior coisa que tem (...) colocam coisas dentro de propósito". Outra diz: "Não são crianças que vêm no início do ano e não sabem (...) porque eles não têm em casa, não têm banheiro, não têm higiene alguma. Mas essas crianças estão na sétima série".

Ao mesmo tempo em que os professores se queixam e manifestam preocupação com essas atitudes dos alunos, eles reconhecem que as condições em que a maioria deles vive em suas casas não propiciam atitudes de cuidado com as coisas, nem incentivam hábitos de higiene.

Os valores atribuídos a atitudes de respeito e cuidado com as coisas têm que ser trabalhados na escola, com muita habilidade por parte do professor, 
para não reforçar sentimentos de baixa auto-estima, que as crianças já trazem pela sua situação social. Tentamos orientar as discussões no sentido de leválos a compreender por esses comportamentos dos adolescentes, que são expressões de suas angústias, frustrações e falta de perspectiva. Isso não signifi$\mathrm{ca}$, entretanto, que o professor não trabalhe essas questões. Ao contrário, significa, que o ponto de partida para qualquer ação pedagógica nesse sentido deve ser o de reconhecimento dos motivos que impulsionam a forma de agir dos adolescentes. Imbuído de uma postura ética de respeito às diferenças, o professor poderá criativamente encontrar formas de incentivar em seus alunos atitudes de cuidado com o entorno.

\section{Em relação aos colegas}

Os professores têm muitas queixas em relação à forma de relacionamento entre os alunos: com muita agressividade e violência. Uma professora expressou-se da seguinte forma: "A violência para eles é normal. A gente fica sabendo de cada estória de violência!" Outra professora relatou na quarta reunião, um acontecimento dramático que ocorreu em sala de aula: "Foi terrível! Um menino da sétima série estava estrangulando a colega na sala de aula. Eu fiquei em pânico, tentei separar, mas não consegui. Se não fosse outro menino ajudar, o pior teria acontecido... a menina já estava roxa".

Os professores atribuem grande parte da violência que ocorre na escola, à violência que muitas crianças sofrem na família, como expressa uma professora: "A violência doméstica que eles sofrem dos pais se reproduz aqui na escola. Nesses dias, veio uma criança com as marcas de agressão no rosto... a mãe havia dado socos perto do olho... ficaram as marcas do anel que ela estava usando no momento da agressão..." .

Tentamos discutir com os professores, observando que, além da violência em família, há formas de violência social com que esses alunos se defrontam cotidianamente: a violência de não poder satisfazer necessidades básicas de alimentação, vestimenta e moradia; a violência de não ver perspectivas futuras; a violência da agressão constante por um convite ao consumo para o qual se sentem impossibilitados.

É consenso no âmbito das teorias pedagógicas que a escola, em geral, embora seja uma frente de luta contra a violência, ao mesmo tempo, contém, em algumas de suas práticas, elementos que podem ser vivenciados pelos alu- 
nos como formas de violência, como, por exemplo, procedimentos avaliativos que desconhecem o contexto em que os conhecimentos são produzidos, ignorando os saberes que os alunos trazem e cobrando resultados de um ensino centrado, sobretudo, na palavra do professor e na memorização.

Orientar os alunos, inseridos em um contexto de violência, para que desenvolvam uma interação social construtiva é um grande desafio para os professores.

Acreditamos que as ações educativas que propusemos podem auxiliar o professor nessa tarefa, na medida em que possibilitam o alívio de tensões de uma forma socialmente aceitável, permitem o exercício de outros papéis sociais colocando-se no lugar do outro, abrem um espaço para a tomada de consciência das implicações e conseqüências das suas ações e dos outros, criando oportunidade para a reflexão sobre questões éticas.

\section{Em relação à sala de aula}

Os professores queixam-se muito do desinteresse, da falta de compromisso dos alunos e da indisciplina. Uma professora expressou-se da seguinte forma: "O maior problema desta escola é que os alunos não se importam se vão ser reprovados, não se importam com a nota que vão tirar, não estão nem aí, se vão tirar I ou S" (30.9.2002).

Em uma das reuniões, o grupo de professores apresentou para a equipe de pesquisa uma cena de psicodrama, na qual eles atuavam como alunos e uma das professoras fazia o prório papel de professora. Essa explicava no quadro sobre "hemisférios e meridianos", enquanto os "alunos" falavam em voz alta, brigavam uns com os outros, saíam da sala, jogavam papeizinhos etc. A "professora", tentando dominar a situação, ameaça os alunos com provas ou com o "caderno de ocorrências". Não conseguindo a atenção dos alunos a "professora" abandona a sala e diz que vai chamar a direção. Ao dar o sinal, os alunos gritam e saem da sala em busca da merenda escolar. Depois da cena apresentada, uma professora resume o pensamento do grupo:

Queríamos mostrar a nossa realidade escolar, mas ela é multiplicada mais ou menos por uns quarenta e não por meia dúzia. É assim: um conversa ali, o outro olha revistinha, outros arrastam cadeiras, outro arranca as lascas da cadeira e joga nos colegas, o outro assobia... 
Outra professora comenta: "Se a gente está bem, até consegue fechar o olho, faz mil coisas".

É também referido o desgaste psicológico que toma conta do professor "é todo esse lado psicológico que a gente precisa ter, uma certa paciência... às vezes respirar fundo para não sair correndo... o que mais acontece é no terceiro período, é hora da merenda".

Outro depoimento reporta-se à tentativa de realizar debate com os alunos: "Eu tento fazer debates com eles, fazer com que parem de conversar e colaborem, mas não é fácil. No geral, o índice de indisciplina e de notas baixas foi muito grande neste semestre".

A questão da avaliação, das notas atribuídas aos alunos e da reprovação, apareceu muitas vezes na fala das professoras, nessa ocasião. Às vezes expressam sua preocupação com os índices de reprovação. Ao mesmo tempo, as advertências dos professores são vistas por eles próprios como uma possibilidade de incentivar o aluno ao estudo. Diz uma professora:

Eu coloquei a realidade para eles visualizarem e, casualmente, entreguei os boletins para eles hoje, e falei que, como estão eles iriam reprovar (...). Nenhum aluno tirou $\mathrm{S}$ em todas as disciplinas, todos tiraram I, que é "insuficiente", em alguma disciplina. Isto é um caso grave, comentei com eles.

Os professores reconhecem, entretanto, a inutilidade desse procedimento, assim se expressando: "Eles não estão nem aí, se vão tirar I ou S". No entanto, a previsão de reprovação e as notas baixas podem aumentar sentimentos de baixa auto-estima, muito presentes em crianças de classes desfavorecidas.

A questão da avaliação é muito discutida no âmbito educacional. As escolas em geral manifestam uma concepção de ensino que Paulo Freire (1997) chamou de "educação bancária", isto é, o professor deposita uma dose de conhecimentos no aluno e espera a devolução com juros.

A seguir discutimos a importância de que os conteúdos transmitidos em sala de aula tenham um significado para o aluno, para que ele se sinta envolvido. Muitas vezes, no contexto das escolas, os conteúdos são abordados de uma forma distante da realidade do aluno, sem a sua participação, exigindo somente memorização, não construindo realmente conhecimentos. Além disso, se a avaliação constitui uma ameaça de perda da auto-estima para os alunos, ela gera 
o medo, que pode se manifestar na forma de indiferença ou em comportamentos agressivos.

Outra questão discutida após a cena de teatro foi referente ao "tema de casa". Um professor reclama do desinteresse dos alunos em relação ao tema: "Disse que não fez o tema, porque não veio na aula, mas não veio há três semanas... Por que não foi atrás? Eles reclamam, mas não fizeram, então têm a nota que merecem, pois a falta não justifica..."

Nesse contexto, discutimos com os professores sobre a real importância do tema de casa na aprendizagem dos alunos.

Uma das idéias que surgiu sobre os temas de casa foi que os professores construíssem algumas normas com os alunos a esse respeito, ouvindo o que eles têm a dizer, examinando as suas propostas e incentivando-os a justi-

ficarem as suas idéias com argumentos, com vistas a chegar a um consenso. É fundamental, entretanto, que o professor esteja realmente aberto para o diálogo, isto é, esteja disposto a aceitar as novas formas de ação que serão definidas por meio dele. Esse procedimento poderá constituir um momento pedagógico significativo para a formação da cidadania.

\section{Resistência e abertura a mudanças}

Os professores durante o período da experiência demonstraram que a sua prática cotidiana é permeada por momentos de desânimo e pessimismo e por momentos de entusiasmo, de busca de transformações e de satisfação com a sua atuação pedagógica. Quem já foi professor pode compreender bem esses sentimentos. Nos momentos de desânimo, procuramos atuar no sentido de ouvir-lhes as queixas, deixar que expressassem seus conflitos, e compartiIhassem seus sentimentos com o grupo. Às vezes, manifestavam certo sentimento de perplexidade e impotência, como constatamos na fala de uma professora:

Nossos alunos são desmotivados e isso nos contagia. (...). Eu acho que muitas coisas que vocês colocam são difíceis de trabalhar, não consigo enquadrar no conteúdo... Eu descobri que eles gostam de vídeo, eu já tentei várias coisas para chamar a atenção, mas o que eles gostam é de uma coisa imediata, que eles não precisem pensar muito. 
Mesmo na expressão desses momentos, afloram, entretanto, manifestações de esperança e crítica. Essa mesma professora diz na seqüência:

A gente gostaria que vocês entrassem e sentissem eles, para encontrarmos juntos uma luz no fim do túnel, coisa que nós não estamos encontrando. É claro que nosso ensino ainda continua na idade da pedra, cuspindo o conteúdo na cara do aluno. Tudo evolui, menos a educação. O dinheiro é pouco, e dentro desse contexto é que a gente se encontra... O jeito é não se deixar contagiar por aquela falta de vontade, por aquele "nada querendo fazer", com aquela monotonia deles, com aquela falta de educação".

Assumindo uma atitude de compreensão dos problemas que o professor enfrenta em seu cotidiano, tentamos incentivar a realização de experiências em sala de aula, nas quais os alunos sejam ativos, participantes, possam externar posicionamentos, construindo conhecimentos que Ihes permitam a vivência de sucesso na escola. Conforme depoimento de professores, as sextas séries da escola estão com um nível de aprendizagem muito baixo. $\bigcirc$ insucesso escolar certamente provoca frustrações. É um conhecimento incontestável no âmbito da Psicologia que a frustração gera agressividade. Nessa perspectiva, o insucesso escolar pode contribuir para um aumento da agressividade, já existente nesses adolescentes devido aos inúmeros conflitos e frustrações que fazem parte do seu cotidiano. Tentando resolver a questão, a escola tem contado com uma intervenção pedagógica dos órgãos competentes, e, conforme palavras de uma professora: "Estamos, primeiramente, fazendo um levantamento de dados para levar à Secretaria, para começarmos a traçar ações concretas para atingir a finalidade".

Uma das queixas mais freqüentes dos professores refere-se ao número excessivo de alunos na sala de aula: aproximadamente 40. Concordamos que esse fato dificulta muito o trabalho do professor.

Os professores apontaram também a exigência de cumprir conteúdos curriculares como um fator que dificulta a sua ação pedagógica.

\section{Orientação em relação a sexo e drogas}

De maneira geral, pudemos observar a preocupação de orientar os alunos quanto a drogas e sexo. Essa necessidade foi expressa pelos próprios alu- 
nos em um questionário, no qual os professores solicitaram que eles se manifestassem a respeito de temas sobre os quais desejavam obter mais orientações da escola.

A escola tomou algumas providências nesse sentido. Uma delas foi a realização de uma palestra, por um serviço de assistência especializada da prefeitura, "para mostrar aos alunos o perigo da AIDS e como se prevenir", tal como se expressa uma professora.

A palestra, segundo os relatos, foi acompanhada de slides. Segundo uma professora, "no leiaute mostraram figuras das doenças, o que elas causam nos órgãos genitais com cada gravura que chocou muito. Queriam mostrar que é importante usar a camisinha". Segundo o relato de outra professora, "na sala era um silêncio só, e eram só duas pessoas contando, mostrando e explicando". Os docentes notaram que os alunos não perguntavam muito na presença deles, conforme depoimento de uma professora: "Eles olhavam para a gente e ficavam sem jeito. Mas quando eles saíram para tomar chá, os alunos encheram de perguntas. São coisas que estão acontecendo com eles e eles estão bem preocupados". As professoras mostraram surpresa quanto às perguntas feitas pelos alunos, como diz uma professora: "Fizeram cada pergunta! Nossa Senhora! A gente não imagina... tu precisas ouvir. Esta é a turma 54, que tem problemas sérios".

No contexto dessa temática, discutimos com o grupo formas de trabalhar essas temáticas com base na nossa proposta, indicamos e trouxemos material de apoio e procuramos explicitar características do período da adolescência com o objetivo de ampliar a compreensão que os professores têm de seus alunos.

\section{Momentos pedagógicos significativos}

O nosso objetivo ao realizar essa experiência é possibilitar a abertura de espaços na prática educativa para a introdução de mudanças que possibilitem aos alunos a construção de interação social construtiva, minimizando a violência e contribuindo para a formação da cidadania. Nossa expectativa não é de conseguir mudanças radicais, mas de, com base em algumas experiências realizadas na sala de aula, e em reflexão realizada a respeito delas, possibilitar a emergência do que denominamos momentos pedagógicos significativos.

Definimos como momentos pedagógicos significativos experiências orientadas pelos professores que oferecem condições para o desenvolvimento da 
personalidade do aluno, ampliando os seus conhecimentos, melhorando a sua auto-estima, auxiliando-o a formar uma identidade moral construtiva, e contribuindo para a sua participação como cidadão na solução dos problemas sociais. As interações que ocorrem nesses momentos são concretas e vivas, portanto, cheias de contradições. Essas contradições, pela reflexão e por novas experiências, podem ser gradualmente superadas e recriadas. É importante ressaltar que elas trazem sempre a marca do real, são, portanto, imperfeitas e sempre susceptíveis de transformações.

Destacamos como momentos pedagógicos significativos:

- apresentações de psicodrama por grupos de adolescentes, que tinham como tema a gravidez na adolescência;

- a discussão em torno dilema de Heinz de Kohlberg e a criação de dilemas por grupos de alunos, tendo como temáticas: drogas, sexo, gravidez e problemas de família, que foram discutidos e dramatizados pelos alunos;

- ações de solidariedade dos alunos para com uma colega e para com uma professora.

A seguir, discutiremos esses momentos.

\section{Dramatizando conflitos}

Em uma das reuniões, um dos professores trouxe dois grupos de alunos, para apresentarem uma cena de teatro criada por eles próprios à equipe de pesquisa e aos professores participantes dos encontros. No início, o professor disse: "A intenção foi buscar alguma coisa dinâmica, prática, singela. Eles criaram o dilema e, a partir do dilema, criaram a solução". A escolha dos grupos que apresentaram a cena foi feita por todos os alunos de uma forma democrática, constituindo também um momento pedagógico significativo.

Na primeira dramatização, os alunos se apresentaram, dizendo o nome e o papel que desempenhavam. A cena apresenta a história de uma menina que quer sair, mas é proibida pela mãe. A mãe precisa ficar uma semana fora, e, ao regressar, descobre que a filha foi embora, por não suportar o modo pelo qual é tratada. Anos mais tarde, a filha retorna à casa, trazendo consigo uma 
filha e o marido. Diz à mãe que não está educando a filha como ela foi educada. A mãe pede desculpas e a filha a perdoa.

Na segunda cena dramatizada, o grupo representou duas famílias, que se encontram para resolver o problema de uma menina de treze anos que está grávida, filha de uma das famílias, e do menino que é o pai da criança, filho do outro casal.

Após as duas apresentações, discutimos com os professores sobre as possibilidades que a dramatização oferece como ação educativa. Após a primeira dramatização, poderia ser solicitada a participação dos espectadores na discussão, de forma semelhante como se procede no teatro-fórum do Teatro do Oprimido. Um ator que fica fora da cena e narra os acontecimentos (o "Curinga") pode perguntar à platéia, o que pensam da atitude da mãe ou da filha e como eles agiriam nesta situação. Após ouvir alguns posicionamentos, o narrador pode solicitar que um dos espectadores (ou mais) represente um dos papéis na cena. Nessa cena, pode ser discutida a questão de valores como afeto, respeito ao outro, responsabilidade, perdão, liberdade etc.

$\mathrm{Na}$ segunda cena, a discussão posterior pode ser feita a partir de muitas questões que a própria platéia coloca, incentivada pelo narrador, abrangendo temas como responsabilidade, capacidade de assumir as suas ações, gravidez na adolescência, relacionamento com os pais, entre outros.

\section{Criando e discutindo dilemas}

Uma das professoras relatou em reunião uma experiência com os alunos, em que eles discutiram o dilema de Heinz em Kohlberg ( 1984 ). Eles deveriam posicionar-se quanto à atitude do marido que roubou o remédio para salvar a esposa, visto que não possuía a quantia necessária para pagá-lo, após ter sido negado pelo farmacêutico o seu fornecimento. Segundo Kohlberg, o desenvolvimento da consciência moral possui uma lógica interna correspondente a processos de aprendizagem, existentes nos diferentes estágios de desenvolvimento. Ele interpreta a passagem de um estágio de julgamento moral a outro superior como o resultado de um processo construtivo, que possibilita ao indivíduo explicar em que sentido os julgamentos correspondentes aos estágios anteriores eram errados. As estruturas cognitivas que estão na base dos julgamentos morais correspondentes a cada estágio se constroem por um processo de reorganização criativa das aquisições cognitivas dos estágios ante- 
riores, quando o indivíduo se confronta com problemas que não consegue resolver e que reaparecem freqüentemente (Habermas, 1989).

Segundo o relato da professora, a maioria dos alunos respondeu que Heinz deveria roubar o remédio, porque o farmacêutico havia roubado antes, cobrando um valor muito além do preço. A partir desse relato, introduzimos as linhas gerais da teoria do desenvolvimento moral de Kohlberg, relacionando os estágios do desenvolvimento com a forma de as crianças e os adolescentes justificarem seus posicionamentos. Detivemos-nos mais no estágio da adolescência, abordando questões sobre as possibilidades que se abrem nesse estágio para a realização de julgamentos morais com base em princípios e valores, para a contestação e exame de valores de sua cultura, até então não questionados e tidos como válidos.

Um dos professores relatou a ação realizada em sala de aula também referente a dilemas. Nessa experiência, propôs-se o seguinte dilema: "Uma menina por volta dos treze anos namora um rapaz mais velho. Os pais não aceitam o namoro. No final, ela engravida". Segundo depoimento do professor

...houve reflexão, discussão, questionamentos. Elaborei também umas questões e eles responderam. Foi bom, eles se envolveram bastante, se posicionaram. Foi legal. Também sugeri que dramatizassem. Formaram grupos, onde cada grupo dramatizou a seu modo. Eles foram bem criativos. Penso que ficou alguma coisa... Ainda trabalhei o Português. Vale a pena deixar de dar uma aula com conteúdos curriculares, para se fazer um trabalho diferente. (...) Falei que eles eram muito bons como juízes e atores também. Eles ficaram muito contentes. Isso levanta a auto-estima deles.

Outra professora expressou a sua aprovação ao trabalho, dizendo: "Eu acho ótimo trabalhar com o dilema como P.fez, porque entra-se no simbolismo, aí eles se sentem a vontade para representar e pôr para fora".

Uma das professoras trabalhou com dilemas relacionados a sexo e ao uso de drogas. Inicialmente, ela solicitou aos alunos que elaborassem por escrito dilemas com essas temáticas. Em uma das reuniões, ela leu para nós o dilema criado por uma adolescente:

Ela tinha somente trezes anos, sua vida não era boa, sua mãe não deixava ela fazer nada que ela gostasse mesmo. Certo dia, foi convidada para ir a uma festa. 
Violência na escola...

Sua mãe a deixou ir somente com a condição de que levasse seu irmão mais novo, de apenas três anos. Na festa, a menina ficou com um rapaz de quinze anos. Já era sete horas da noite e o menino começou a chorar, pois sabia que seu padrasto ia bater nele. $\bigcirc$ menino falou que se ela quisesse poderia ir morar com ele. A menina apavorada aceitou. Levou seu irmão até um pedaço do caminho e pediu a uma amiga para levá-lo em casa. A menina sofreu muito, se drogou e se prostituiu. Hoje, com dezesseis anos, está criando duas filhas sozinha, pois o menino que a convidou para ir morar junto com ele a deixou.

Conforme o depoimento da professora, o dilema criado pela aluna serviu como ponto de partida para a discussão em torno de relações familiares e papéis sociais de pai e mãe, castigo físico, cooperação, responsabilidade e autonomia.

\section{Sendo solidário}

A análise das reuniões possibilitou identificar momentos pedagógicos significativos em que emergiram sentimentos de solidariedade. Um deles diz respeito à solidariedade com uma colega grávida e o outro em relação à professora que havia sofrido um aborto, necessitando, por isso, afastar-se da escola em licença médica.

Em uma das reuniões, uma professora relatou o fato de uma aluna adolescente grávida, que estava muito retraída na turma. Ela então incentivou os colegas a confeccionarem um cartão para ela. Segundo relato da professora, a maioria dos alunos cumpriu a tarefa com bastante entusiasmo. A partir desse gesto, a adolescente tornou-se menos retraída, interagindo mais com colegas e professores. Conforme as palavras da professora: "acho que, de alguma forma, aquilo mexeu com ela". Na reunião, compartilhamos com as professoras o pensamento sobre a importância de criar momentos como esse no cotidiano escolar, para alcançar transformações que possibilitem a emergência de interação social construtiva, minimizando a violência.

Em outra reunião, uma das professoras relatou que, ao explicar porque estava de licença expressando a sua tristeza por não ter podido levar adiante a gravidez, os alunos aproximaram-se dela, mostrando sentimentos de solidariedade e fazendo perguntas. Ela expressou essa percepção com as seguintes palavras: 
Eu acho que muito mudou por causa do aborto que eu tive. Agora eles vêm e me perguntam várias coisas, o que antes eles não faziam. Eu acho que me aproximei mais deles. Eu cheguei na sala e falei para eles e expliquei por que não estava dando aula para eles... Várias vezes eles vinham me perguntar como eu estava, se eu estava bem.

A professora reconheceu que a atitude dos alunos foi ocasionada pela forma de ela lidar com eles, pois, ao compartilhar com eles a sua tristeza, despertou sentimentos de solidariedade. Manifesta isso dizendo: "Me viram como pessoa e não só como professora".

A solidariedade tem em sua base o sentimento de coisas que temos em comum e nos identificam uns com os outros. Na solidariedade está sempre presente a reciprocidade, a troca, a capacidade de pôr-se no lugar do outro, sentir a sua dor e a sua alegria, compartilhar emoções, pensamentos e sentimentos.

\section{CONSIDERAÇÕES FINAIS}

Orientar os alunos inseridos em um contexto de violência no sentido de desenvolverem uma interação social construtiva é um grande desafio para os professores.

O objetivo das diferentes formas de dramatização é estimular em crianças e adolescentes a capacidade para resolver problemas de forma competente, isto é, a comportar-se construtivamente em momentos de conflito, ajudando-os a renunciar à violência, desenvolvendo a capacidade de diálogo e a busca conjunta na solução dos problemas.

Acreditamos que as ações educativas que propusemos podem auxiliar o professor nessa tarefa, na medida em que possibilitam o alívio de tensões de uma forma socialmente aceitável, permitem o exercício de outros papéis sociais pondo-se no lugar do outro, abrem um espaço para a tomada de consciência das implicações e conseqüências das suas ações e dos outros, propiciando a reflexão sobre questões éticas.

As diferentes técnicas de dramatização são apenas sugestões, que devem ser recriadas para as situações específicas que ocorrem em sala de aula. Levando em conta o contexto cultural da escola e os conflitos existentes em determinado momento, o professor, a partir das idéias dos autores podem 
recriar essas técnicas, adequando-as aos objetivos pedagógicos que pretende atingir.

Finalizando queremos destacar que a investigação só foi possível pela participação compromissada dos professores que compartilharam conosco suas alegrias e tristezas, suas realizações e dificuldades, e, sobretudo, trouxeram seus saberes, enraizados na vida concreta da escola. Reconhecemos, em sua disponibilidade de participar da experiência e nas suas manifestações durante esse período, a busca incessante de uma escola melhor, que garanta a dignidade do ser humano.

\section{REFERÊNCIAS BIBLIOGRÁFICAS}

BOAL, A. Jogos para atores e não-atores. Rio de Janeiro: Civilização Brasileira, 2000.

CHAUÍ, M. Convite à filosofia. São Paulo: Ática, 1995.

COLOMBIER, C.; MANGEL, G.; PERDRIAULT, M. A Violência na escola .2.ed. São Paulo: Summus, 1989.

CULLEN, C. A. Autonomia moral, participatión democrática y cuidado del otro. Buenos Aires: Novedades Educativas, 1996.

ERIKSON, E. H. Identidade: juventude e crise. Rio de Janeiro: Zahar, 1976.

ESTRELA, M. T. Relação pedagógica, disciplina e indisciplina na aula. 2.ed. Porto: Porto Editora; LDA, 1994.

FALLER, K.; KERNTKE, W.; WACKMANN, M. Konflikte selber/ösen: ein Konfliktmanagement in Schule und Jugendarbeit. Mülheim an der Ruhr: Verlag an der Ruhr, 1996.

FREIRE, P.Medo e ousadia: o cotidiano do professor. 7.ed. Rio de Janeiro: Paz e Terra, 1997. Pedagogia da esperança: um reencontro com a pedagogia do oprimido. Rio de Janeiro: Paz e Terra, 1994. . Pedagogia do oprimido. Rio de Janeiro: Paz e Terra, 1985.

GILLIGAN, C. La moral y la teoria: psicologia del desarrollo femenino. México: Fondo de Cultura Económica, 1994.

HABERMAS, J. Consciência moral e agir comunicativo. Rio de Janeiro: Tempo Brasileiro, 1989.

KOHLBERG, L. Essays on moral development. the psychology of moral development. São Francisco: Harper and Harper, 1984. V. 2 
KNOBEL, M. Normalidade, responsabilidade e psicopatologia da violência na adolescência. in: LEVISKY, D. L. Adolescência e violência: conseqüências da realidade brasileira. Porto Alegre: Artes Médicas, 1997.

KRYNSKI, S. O Adolescente e a violência: um processo em busca da identidade. In. LEVISKY, D. L. Adolescência e violência: conseqüências da realidade brasileira. Porto Alegre: Artes Médicas, 1997.

LEVISKY, D. L. Aspectos do processo de identificação do adolescente na sociedade contemporânea e suas relações com a violência. In: LEVISKY, D. L. Adolescência e violência: conseqüências da realidade brasileira. Porto Alegre: Artes Médicas, 1997.

MARQUES, M. O. Formação do profissional de educação. ljuí: Ed.Unijuí, 2000.

PERRENOUD, P. Práticas pedagógicas, profissão docente e formação: perspectivas sociológicas. Lisboa: Nova Enciclopédia, 1997.

PIAGET, J. O Juízo moral na criança. São Paulo: Summus, 1994.

PUIG, J. M. A Construção da personalidade moral. São Paulo: Ática, 1998.

Ética e valores. métodos para um ensino transversal. São Paulo: Casa do Psicólogo, 1999.

SCHÖN, D. Formar professores como profissionais reflexivos. In: NÓVOA, A. Os Professores e a sua formação. Lisboa: Nova Enciclopédia, 1995.

TARDIF, M. Saberes docentes \& formação profissional. Petrópolis: Vozes, 2002.

WEIL, P.Psicodrama. Rio de Janeiro: Cepa, 1967.

ZEICHNER, K. Novos Caminhos para o practicum: uma perspectiva para os anos 90. In: NÓvOA, A. Os Professores e a sua formação. Lisboa: Dom Quixote, 1995. p. I I 5- 138.

Recebido em: junho 2003

Aprovado para publicação em: junho 2005 